\title{
Recuperación del espacio público para la reducción de la percepción de inseguridad: el caso del fraccionamiento Los Héroes en Puebla, México
}

Recovery of public space to reduce the perception of insecurity: The case of Los Heroes gated community in Puebla, México Juan Manuel Bautista Ramírez*, María de Lourdes Flores Lucero* y María Lourdes Guevara Romero*

Recibido: 09 de julio de 2018

Aceptado: 13 de diciembre de 2018

\begin{abstract}
Resumen
Las malas condiciones del espacio público en fraccionamientos cerrados $^{1}$ en México han incidido en el aumento de la delincuencia, así como de la percepción de inseguridad. Particularmente en el Fraccionamiento Los Héroes, ubicado al sureste de la ciudad de Puebla, se ha observado que la falta de mantenimiento y deterioro continuo de sus espacios públicos han influido en la pérdida de actividad social y en la creación de condiciones óptimas para delinquir, de manera que en 2011 ha sido catalogado por las autoridades locales entre los diez más inseguros. A través de información cualitativa obtenida por observación directa, encuestas y entrevistas a actores clave, en un periodo de 16 meses de trabajo de campo (octubre 2015 a febrero 2017), se buscó conocer y cambiar las condiciones de uso de espacio público, particularmente en dos de los seis parques existentes, el de la 119 y el de la guardería, para disminuir la percepción de inseguridad a través del trabajo articulado y corresponsable entre el sector público y social. El cambio logrado en las condiciones físicas de uno de los parques posibilitó demostrar que el trabajo liderado por jóvenes, con fines ecológicos, permitió modificar la percepción de inseguridad y que los vecinos volvieran a hacer uso del lugar.
\end{abstract}

Palabras clave: delincuencia, espacio público, organización vecinal, percepción de inseguridad.

\begin{abstract}
The bad conditions of public space in gated communities have had an impact on the increase of crime, as well as on the perception of insecurity, in cities such as Puebla. Particularly in the Fraccionamiento Los Héroes, located southeast of said city, it has been observed that the lack of maintenance and continuous deterioration of its public spaces have influenced the loss of social activity and the creation of optimal conditions to commit crimes, so that in 2011 has been cataloged by the authorities among the ten most insecure. Through qualitative information obtained by direct observation, surveys and key actors interviews, in a period of 16 months (October 2015 to February 2017) of field work, we sought to know and change the conditions of use of public space, especially in two of the six parks, the 119 and the guardería, to reduce the perception of insecurity through articulated work and co-responsible between the public and social sectors. The change achieved in the physical conditions of one of the parks allowed to demonstrate that the work led by young people, with ecological purposes, managed to modify the perception of insecurity and that the neighbors returned to make use of the place.
\end{abstract}

Keywords: delinquency, insecurity perception, neighbourhood organization, public space.

* Benemérita Universidad Autónoma de Puebla, Puebla, México. Contacto: bautistaramirezjuanmanuel@gmail.com, lulu.lucero@gmail.com, lourdes.guevarar@gmail.com

Se presentan parte de los resultados de la tesis doctoral La organización social y gubernamental para recuperar el espacio público: una medida contra la delincuencia, y que formó parte del proyecto de investigación Gestión participativa para el mejoramiento de asentamientos urbanos Clave VIEP FLLMING15/16/17/18-G. Financiado por la Vicerrectoría de Investigación y Estudios de Posgrado.

Cómo citar: Bautista Ramírez, J.M., Flores Lucero, M.L. y Guevara Romero, M.L. (2018). Recuperación del espacio público para la reducción de la percepción de inseguridad: el caso del fraccionamiento Los Héroes en Puebla, México. Revista de Urbanismo, 39, 1-17. https://doi.org/10.5354/0717-5051.2018.50489

\footnotetext{
1 Se considera un fraccionamiento cerrado en el sentido de gated community ya que cumple con el hecho de tener accesos controlados, como lo señala Roitman (2004).
} 


\section{Introducción}

El Plan Nacional de Desarrollo 2012-2018 señala que "entre 2010 y 2011 las víctimas del delito en México aumentaron de 17.8 a 18.7 millones" (Gobierno de la República, 2013, p. 33); y establece que su prevención debe quedar en manos de la sociedad civil. Apoyado en autores como Azaola (2013), el Programa Nacional para la Prevención Social de la Violencia y la Delincuencia (PNPSVD) dice que, a través de la acción comunitaria, los ciudadanos son los encargados de realizar las actividades necesarias para reducir los índices delictivos al hacer labores que lleven, entre otras cosas, a la mejora de los espacios públicos. También señala a la delincuencia como un fenómeno multicausal, y que las condiciones del espacio público pueden ser determinantes para su incremento, por lo que considera necesaria su recuperación por parte de los habitantes de las colonias y fraccionamientos para mejorar su vida social y con ello abatir la delincuencia y mejorar su percepción de seguridad. Por ello, la existencia de espacios públicos adecuados es fundamental para que se lleven a cabo actividades que permitan la convivencia pacífica, así como la promoción del respeto y la tolerancia entre los habitantes de una comunidad. Sugiere la recuperación de los espacios públicos por parte de los habitantes de las colonias y fraccionamientos para mejorar su vida social y con ello abatir la delincuencia y mejorar su percepción de seguridad.

Asimismo, el Plan Nacional de Desarrollo 2001-2006, abre la posibilidad de que las grandes empresas tomen control de la construcción de vivienda en México. Esto ha permitido la formación de enormes conjuntos de casas unifamiliares, de hasta cerca de 20,000 viviendas, en la periferia de las ciudades, con falta de equipamientos y servicios. En ellos se ha privilegiado la obtención de altas tasas de ganancia, antes que la calidad de vida de los habitantes (Esquivel, Maya y Cervantes, 2005).

Si bien no hay estudios que señalen una relación directa entre espacio y violencia, no podemos negar que la falta de espacio habitable impide, a nivel familiar, la cohesión entre sus miembros anula la intimidad y expulsa a sus integrantes a la calle, particularmente a los jóvenes, con todos los peligros de seguridad que existen (Esquivel et al., 2005)
En este contexto, y con el fin de analizar las formas en que el gobierno y la sociedad están reaccionando ante la delincuencia en fraccionamientos cerrados, se estudió el caso del fraccionamiento cerrado Los Héroes en Puebla, México, ya que es un ejemplo de las políticas de construcción descritas por Esquivel et al. (2005), y que a menos de 5 años de su desarrollo, se consideró entre las 10 colonias con mayor índice de delincuencia en el municipio de Puebla (Anónimo, Periódico digital, 2011). En encuestas aplicadas a los vecinos, señalan que los delitos más comunes son robo a transeúnte, de autopartes y a casa habitación. En este fraccionamiento encontramos condiciones óptimas para delinquir como son el abandono y mal estado de los espacios públicos, características morfológicas urbanas, falta de organización vecinal e indiferencia gubernamental.

Fonseca (2014) señala la importancia del espacio público como elemento fundamental en la vida diaria, lugar de encuentro y cohesión comunitaria. El cual, al sufrir un deterioro continuo, pierde su uso normal para convertirse en espacios donde posiblemente se realicen actos delictivos. Por ello, nos preguntamos ¿Cómo se puede incidir en la promoción de acciones conjuntas entre autoridades, vecinos y otras instituciones para la recuperación del espacio público y, con ello, influir en la disminución de la inseguridad y el fortalecimiento de las relaciones vecinales en fraccionamientos cerrados?

En fraccionamientos como Los Héroes, es necesaria la participación conjunta entre autoridades, vecinos y otras instituciones, que aún son confiables para la población, para promover la recuperación de los espacios públicos e incidir en la disminución de la percepción de inseguridad.

Con base en lo anterior, nuestro objetivo es analizar las formas en que el gobierno y la sociedad están reaccionando ante la delincuencia en fraccionamientos cerrados, con el fin de realizar propuestas que coadyuven a la promoción de acciones conjuntas para la recuperación del uso de espacios públicos $y$, con ello, la prevención $y$ disminución de la delincuencia. 


\section{Metodología}

Se realizó un análisis documental bibliográfico y de instrumentos oficiales. Los principales autores estudiados fueron Averdijk (2011), y Wilson \& Kelling (2006), quienes detallan condiciones territoriales específicas desde las que se percibe la inseguridad y cómo afectan las costumbres y relaciones de los ciudadanos, así como la manera en que actualmente se construyen fraccionamientos (Esquivel et al., 2005). Kessler (2009) y Jasso López (2013) analizan el sentimiento de inseguridad al transitar por espacios públicos. Respecto a los instrumentos oficiales se analizaron los concernientes al espacio público y la seguridad pública. Destacan, la Ley de fraccionamientos y acciones urbanísticas del Estado Libre y Soberano de Puebla (2003), la Ley que regula el régimen de propiedad en condominio para el Estado de Puebla (2011), el Plan Nacional de Desarrollo 2013-2018, el Programa Nacional para la Prevención Social de la Violencia y la Delincuencia 2014-2018, y el Reglamento del Servicio Profesional de Carrera Policial de la Secretaría de Seguridad Pública y Tránsito Municipal (2014).

Para conocer el trabajo de la policía, así como la percepción sobre la delincuencia y el trabajo realizado para aminorarla, se realizaron tres entrevistas semidirigidas al Oficial Mayor de la Secretaria de Seguridad Pública y Tránsito del municipio de Puebla, al director de la escuela secundaria ubicada en el fraccionamiento y al secretario del Consejo Ciudadano de Seguridad Pública del Estado de Puebla, así como a 15 actores clave del fraccionamiento Los Héroes.

La investigación-acción (Checkland, 1993; Lewin, 1946) propone la participación del investigador en las actividades propias de los eventos que está estudiando, de tal manera que puede crear lazos de confianza para acercarse de una manera más informal con los actores sociales; asimismo, permite compartir experiencias de reflexión, enseñanza y aprendizaje. Con base en esta teoría, se realizaron recorridos de campo para diagnosticar las condiciones de los principales espacios percibidos como inseguros y con incidencia delictiva, además de contactar a la organización vecinal "Salvemos los parques". A partir de octubre de 2015 y hasta febrero de 2017, con jornadas semanales de tres a cuatro horas cada domingo, se trabajó con esta organización en la recuperación de dos de los parques del fraccionamiento, el de la 119 y el de la guardería. ${ }^{1}$

\section{Espacio público deteriorado: paso a la inseguridad y delincuencia}

Los espacios públicos son sitios donde las personas pueden realizar actividades que llegan a fomentar el fortalecimiento de identidades y cohesión por las actividades en común. Asimismo, permite el acceso de los usuarios las 24 horas del día, particularmente en espacios a escala barrial (Fonseca, 2014); es decir, son espacios comunitarios para convivir y establecer lazos sociales (Maya y Cervantes, 2008)

Por sus usos, podemos identificar centros comerciales, vías públicas y parques; el presente estudio se realizó en estos últimos, ya que son espacios destinados a la recreación, pero que, por sus características físicas, están abiertos al tránsito de cualquier persona.

Los espacios públicos, que van dejando de recibir los servicios urbanos, se convierten en lo que Wilson y Kelling (2006) Ilaman zonas de decadencia urbana. En ellas, es notorio el descuido, es muy probable que exista poca supervisión de los vecinos y la policía, dando paso a la facilidad para cometer actos delictivos. En la medida en que en un lugar se comete un delito, es más probable que se cometan varios más. Así, estos espacios, a los que los autores denominan "ventanas rotas", se convierten en lugares intransitables y peligrosos, y los vecinos son más susceptibles de quedar atrapados en zonas de degeneración urbana. El mal estado del entorno que permite que los delitos empiecen a surgir, fomentan un sentimiento de inseguridad (Jasso López, 2013; Kessler, 2009).

De acuerdo con la Real Academia de la Lengua Española, el delito es considerado como un daño a las personas. En entrevista con el Oficial Mayor de Seguridad Pública en del municipio de Puebla, nos aclaró que un delito se refiere al daño en los bienes de la persona (por

\footnotetext{
1 El caso de estudio es el Fraccionamiento Los Héroes, pero solo se actuó en dos parques. Sin embargo, en el parque de la guardería únicamente se trabajó tres meses al inicio de 2016 ya que se encontró con muy poca respuesta por parte de los vecinos y de las autoridades de la guardería.
} 
ejemplo: el robo), mientras que un crimen es un delito grave, pues daña a las personas en su persona (por ejemplo: asesinato o secuestro).

Un lugar donde se ha cometido un delito modifica los hábitos y costumbres de los habitantes ya que lo califica como peligroso. Pensar que ahí se puede ser víctima de un acto delictivo es el sentimiento de inseguridad que Kessler (2009) y Jasso López (2013) mencionan. El sentirse inseguro es una percepción personal, que boca a boca puede convertirse en social, estigmatizando a un sitio, el cual empieza a ser abandonado; volviéndose más proclive a convertirse en un lugar propicio para el delito.

Dejar de pasar por un lugar, por ejemplo, puede ser total, cuando el lugar se califica como altamente peligroso; o por defecto, cuando las precauciones al transitar por ese espacio dependen del horario o de las actividades que uno realice, y que los demás hagan ahí, ya que las personas que tienen rutinas diarias $y$ actividades riesgosas provocan que más fácilmente se conviertan en víctimas del delito (Averdijk, 2011). Así, la restricción de la movilidad y el cambio de hábitos dependen del sentimiento de inseguridad en ciertos espacios.

El grupo Cohesión Comunitaria (2010), Dammert (2003), y Larsen, B. Ф., Kleif, H. B., \& Kolodziejczyk, C. (2015), proponen la participación ciudadana en la apropiación de los espacios públicos para contrarrestar a la delincuencia y la violencia. Para ello, Duhau y Giglia (2008) consideran que "no necesariamente se debe suponer la existencia de "identidades colectivas" o de "comunidades locales, pero si una cierta dosis de arraigo, que definimos como el estar vinculado a un lugar mediante la inserción del sujeto en redes de relaciones relativamente densas, situadas en el espacio local" (p.24).

Por su parte, Maya y Cervantes (2008) consideran que las relaciones sociales se dan con base en el uso de los espacios exteriores y su relación con los servicios urbanos. En este sentido, la comunidad vecinal se considera conforme a la existencia de un sentido de arraigo y compromiso con aquellos con los que se comparte un espacio, para cumplir con algunas acciones en común.

Simultáneamente, Bauman (2009), nos dice que en la actualidad las instituciones se han debilitado y el Estado ha perdido fuerza para cumplir con sus funciones, entre las que se encuentran el mantenimiento del espacio público y la seguridad ciudadana. Por su parte, Touraine (2000), considera que existe un debilitamiento del Estado producto del neoliberalismo, por ello, muchas de las acciones que antes considerábamos de incumbencia estatal, debemos dejarlas en manos del mercado y entonces pagar por ellas, como es el caso de las empresas de seguridad, así como de las de limpieza y recolección de basura, o el mantenimiento de espacios públicos que, en el caso de conjuntos cerrados queda en manos de los condóminos, o de cierta manera indefinido como veremos en nuestro caso de estudio.

\section{La responsabilidad gubernamental y la sociedad organizada}

Observamos que a través de los instrumentos oficiales se delega la responsabilidad sobre las condiciones de seguridad al ciudadano. En el caso del estado de Puebla, México, por ejemplo, la Ley que regula el régimen de propiedad en condominio para el Estado de Puebla (2011), señala que la responsabilidad del mantenimiento y vigilancia de fraccionamientos cerrados queda en manos de los condóminos; sin embargo, no deja claro qué pasa con fraccionamientos donde se combinan condominios cerrados con zonas abiertas.

Además, los reglamentos de policía de municipio de Puebla (2014), establecen una organización jerárquica y con una delimitación poco clara de responsabilidades y competencias jurisdiccionales. Esto genera un sentimiento de inseguridad en el actuar de los elementos policiacos, y de desconfianza de la ciudadanía en su actuar; lo cual, aunado a la falta de organización vecinal, así como el descuido de los espacios públicos, inciden en el incremento de los índices delictivos.

En una ocasión vi cómo era golpeada una chica; en el momento pasó una patrulla y se pidió a los policías que intervinieran. Ellos no lo hicieron alegando que a ellos no les tocaba patrullar ese lado de la calle, y que si intervenían podían exceder sus funciones (Relato de uno de los vecinos del fraccionamiento Los Héroes).

No debemos olvidar que el espacio público debe ser legalmente regulado por la administración pública y, por 
lo tanto, esta es la responsable de su mantenimiento (Segovia y Jordán, 2005). Sin embargo, el Estado, por omisión, o por incapacidad, paulatinamente ha renunciado a distintas responsabilidades, incluyendo el mantenimiento a los espacios públicos (Bauman, 2009; González, 2015; Touraine, 2000).

Por otro lado, para reducir la percepción de inseguridad se requiere de una buena relación vecinal, la cual se puede ver reflejada en el buen estado del espacio público y privado; por lo que es fundamental reforzar los lazos de confianza entre actores sociales, así como con los institucionales para formar organizaciones que lleven a la apropiación de los espacios por parte de los vecinos (Duhau y Giglia, 2008; Maya y Cervantes, 2008).

La comunidad juega un rol fundamental para crear un sentido de pertenencia e identidad colectiva. La consolidación de la comunidad es vista como un proceso ligado a la disminución de los delitos y de las oportunidades para cometerlos, así como la defensa frente a los extraños o la formación de un espacio social seguro (Dammert, 2003). Así, la sociedad organizada debe suplir las actividades propias de prevención de la delincuencia, manteniendo espacios públicos en buenas condiciones, logrando la disminución de la percepción de inseguridad y, posiblemente la reducción de los índices delictivos.

\section{Los Héroes como caso de estudio}

El fraccionamiento Los Héroes, ubicado al suroriente del municipio de Puebla, fue construido y puesto a la venta entre 2004 y 2007 . Se concibió como un lugar donde vivir en familia, con un ambiente sano y seguro, sin embargo, el principal problema detectado por los habitantes es la delincuencia seguida del deterioro del espacio público.

Está limitado por dos vías principales, la Av. 14 Sur y el Periférico Ecológico. El fraccionamiento se ubica en medio de terrenos baldíos, convirtiéndolo en una "isla urbana" (Duahau y Giglia, 2008) (ver figura 1). Esto influye en que los lugares de trabajo de los vecinos se encuentren muy alejados, por lo que muchas casas están toda la mañana deshabitadas, motivando a que la mayor parte de los robos en casa habitación se den en el transcurso de horas de labores.

Tiene 10,741 viviendas de interés social, y una población aproximada de 40,000 habitantes. Maya y Cervantes (2008) consideran estos fraccionamientos como miniciudades y les llaman Conjuntos habitacionales. En ellos es difícil encontrar organizaciones vecinales por las múltiples diferencias entre los habitantes, según describen los autores.

Es común que padres y madres trabajen fuera del fraccionamiento, pues ahí no hay centros de trabajo, por lo que dejan a sus hijos, y la casa, sin supervisión la mayor parte del día. La edad promedio de los jefes de familia fluctúa entre los 35 y 50 años, y sus hijos tienen como edad mayor los 19 años, aproximadamente, por lo que sus actividades, principalmente, son fuera de la casa y del fraccionamiento. Esto influye en que los lazos comunales sean mínimos. Como señalan Duhau y Giglia (2008), la desconfianza que manifiestan los vecinos es fruto del poco conocimiento de quién vive a un lado, lo que limita el arraigo y las relaciones de vecindad. 


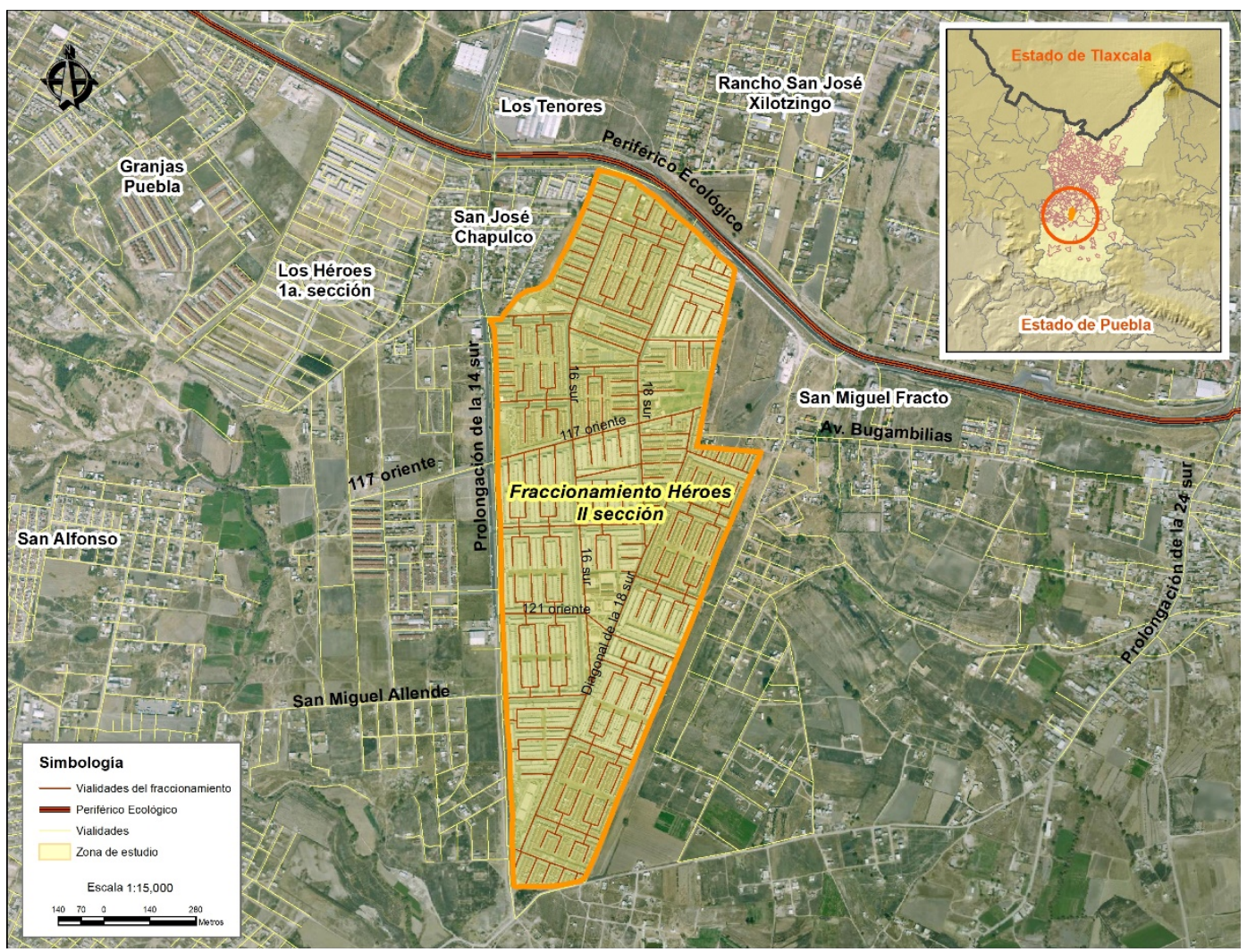

Figura 1. Ubicación del fraccionamiento Los Héroes Puebla.

Fuente: Elaboración propia con base en el Marco Geoestadístico (INEGI, 2018) e imagen de Google Earth, 2018. https://www.google.com.mx/maps/, octubre de 2014.

Encontramos los siguientes factores que están generando condiciones óptimas para la delincuencia:

La magnitud del fraccionamiento (Maya y Cervantes, 2008) y el estar unido a la ciudad únicamente con un puente, además de rodeado por zonas poco habitadas como se aprecia en la figura 1 , lo hacen propicio para delinquir. Tiene ocho accesos que anteriormente tenían plumas de control de acceso, además de que dos de ellos tenían casetas de vigilancia y ahora se encuentran deterioradas o inhabilitadas. El hecho de que las plumas y casetas de vigilancia no funcionen, da lugar al cuestionamiento sobre quién recae la responsabilidad de la seguridad y mantenimiento según lo estipulado para los fraccionamientos cerrados en la Ley de Condominio (Gobierno del Estado, 2011), sobre los condóminos o el gobierno.

La mayor parte de las casas se encuentran dentro de cerradas, con 110 viviendas, en forma de $U$, donde los vecinos suelen poner rejas para impedir el paso, creando aislamiento con el resto del fraccionamiento (figura 2 ). 


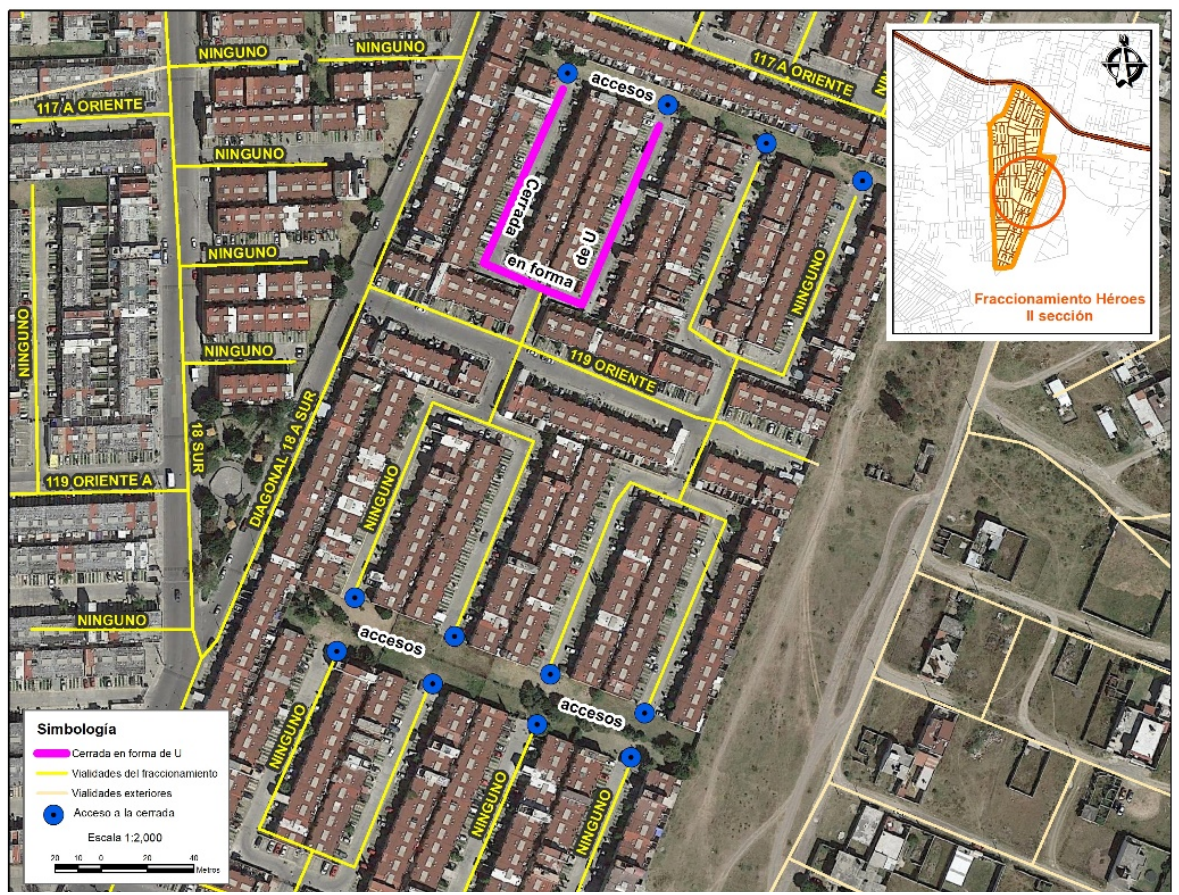

Figura 2. Ejemplo de cerradas.

Fuente: Elaboración propia con base en el Marco Geoestadístico (INEGI, 2018) e imagen de Google Earth, 2018.

Un equipamiento abandonado. Al interior del fraccionamiento existen distintos equipamientos comerciales, educativos y de servicios que permiten la satisfacción de algunas necesidades de los habitantes. Además, en dos de las entradas se encuentran tiendas de conveniencia.

Hay cinco pequeñas plazas comerciales, dos de las cuales, las más grandes, se encuentran prácticamente abandonadas dando pie a la proliferación del comercio informal, tanto en la vía pública, como en casas habitación. Las plazas ocupadas tienen pequeñas tiendas de conveniencia, tortillerías o panaderías.

En el ramo educativo, y como parte de las áreas de donación, el fraccionador construyó cuatro escuelas dos preescolares, primaria y secundaria. La primaria y la secundaria se encuentran cerradas por barda y reja, y fuera de ellas había áreas públicas con palapas para que los padres de familia pudieran esperar a sus hijos, o para que los estudiantes convivieran al salir de clases. Actualmente, estos espacios se encuentran encerrados con una alambrada; esto permite que se conserven en buenas condiciones, pero se ha perdido su uso público, además de ser una barrera que impide que alguien se acerque a las rejas de las escuelas. El director de la secundaria comentó, que la idea de enrejar el parque fue suya ya que todos los días encontraba basura relacionada con el alcoholismo y actos sexuales.

Hay seis parques con juegos infantiles, pistas para andar en bicicleta o patinar, palapas para hacer comidas al aire libre, canchas de basquetbol, y en dos de ellos tienen cancha de futbol rápido cerradas con rejas. Desafortunadamente, todos estos parques no cuentan con alumbrado público interno, sólo con el de la calle, el cual es insuficiente para alumbrar el interior. Las condiciones en las que se encuentran los parques son de total abandono provocando su desuso paulatino (figuras 3,4 y 5). La crecida de la vegetación que rodea los parques impide ver al interior, las palapas y el mobiliario se encuentran pintadas con grafiti. Al interior se encuentra la hierba muy crecida, hay acumulación de basura y hasta excremento humano y animal. 


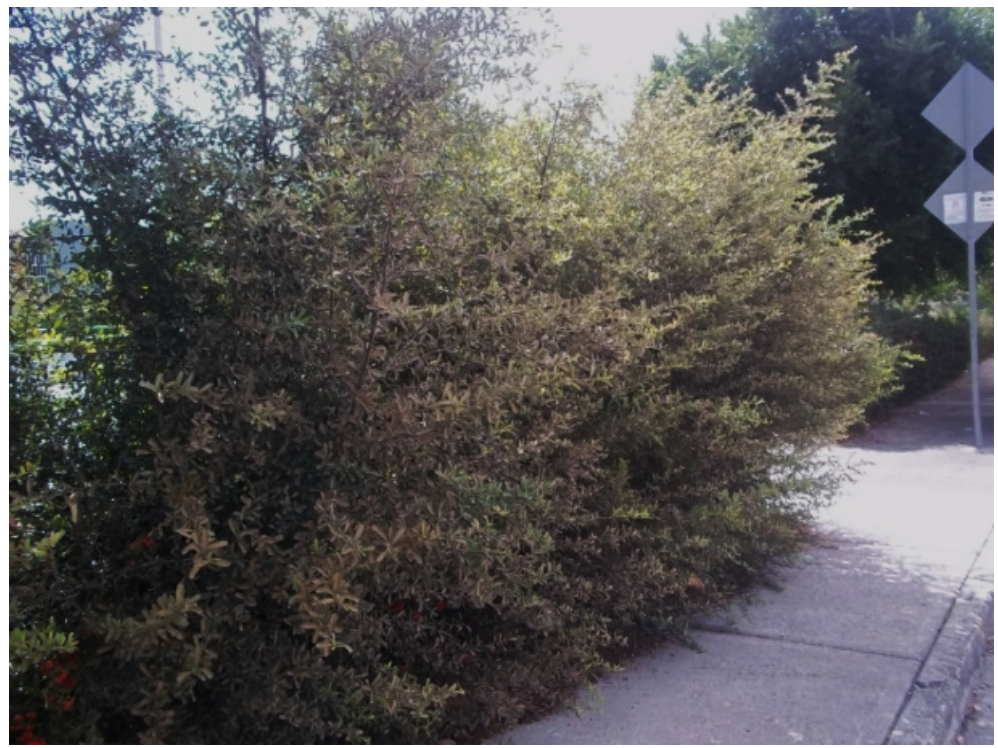

Figura 3. Condiciones de abandono y deterioro en los parques. Arbustos circundantes del parque tapan la vista al interior. Fuente: Juan Manuel Bautista Ramírez, 2015.

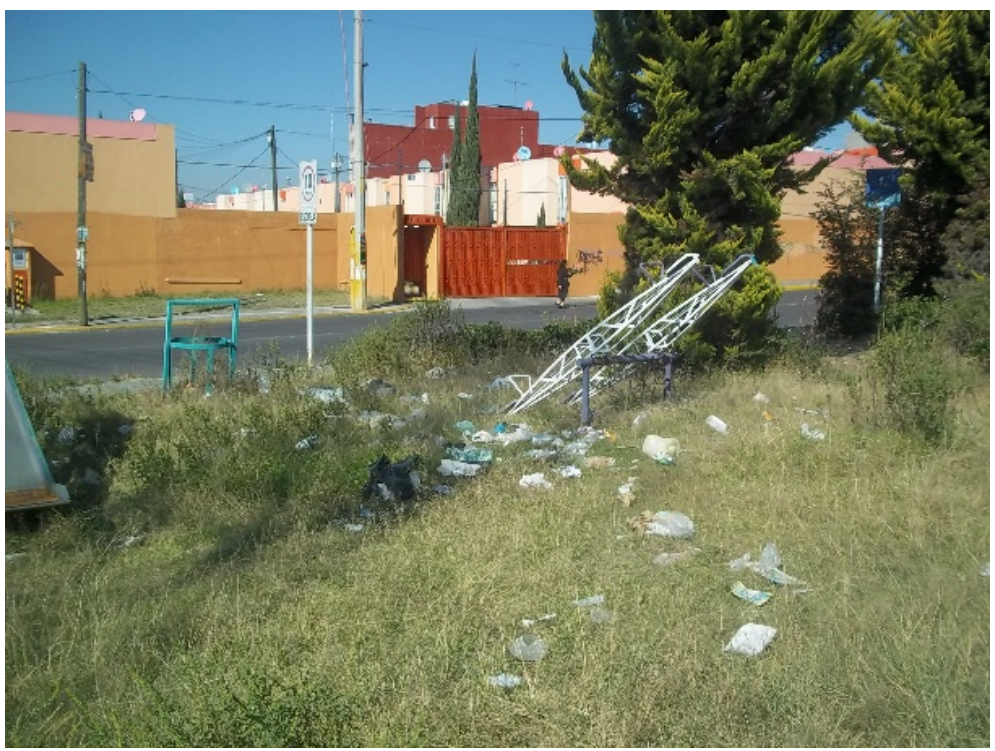

Figura 4. Condiciones de abandono y deterioro en los parques. La basura en los parques afecta las condiciones de salubridad. Fuente: Juan Manuel Bautista Ramírez, 2015. 


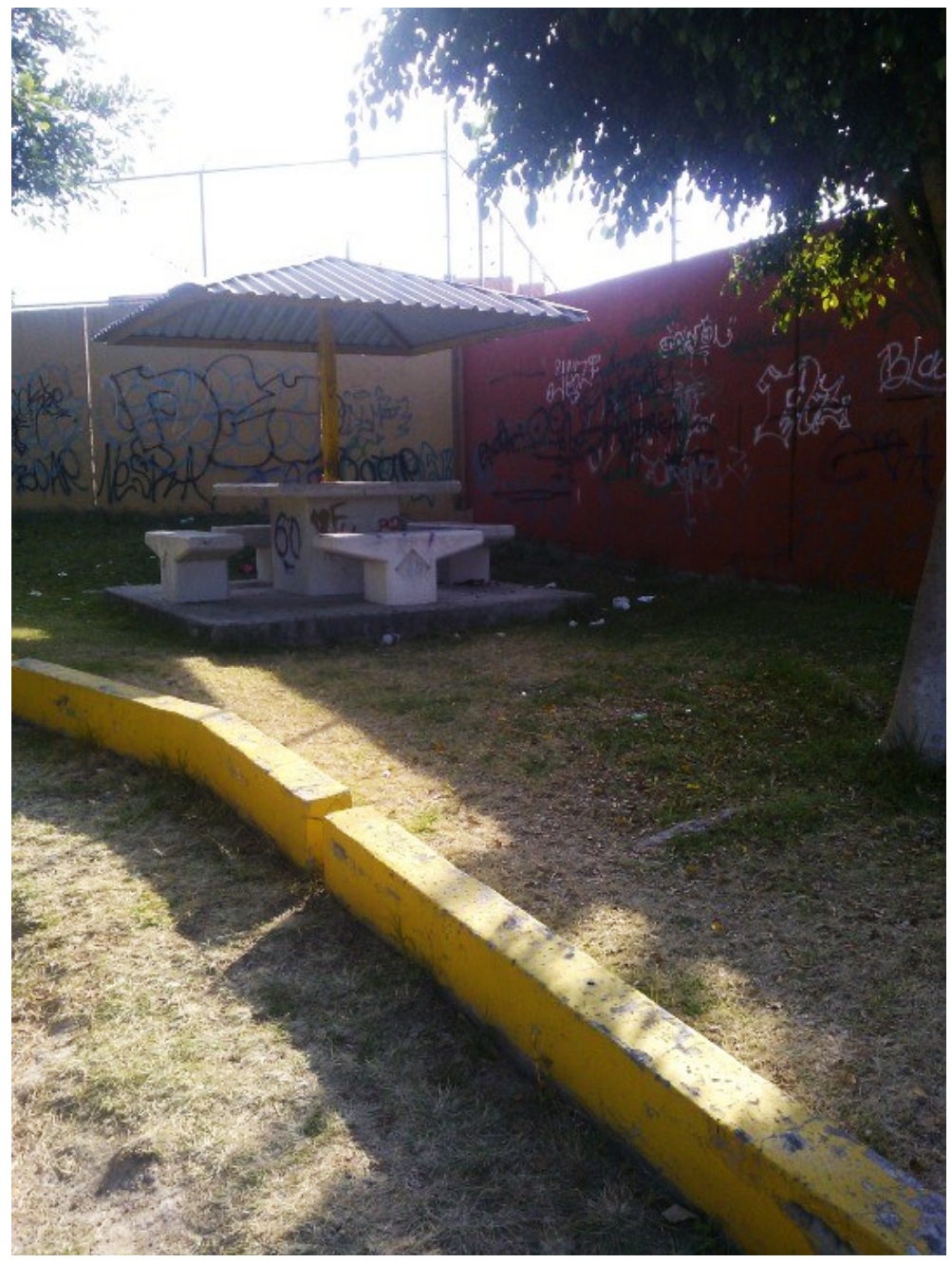

Figura 5. Condiciones de abandono y deterioro en los parques. El grafiti y la basura son constantes, prueba de que no hay vigilancia.

Fuente: Juan Manuel Bautista Ramírez, 2015.

El abandono de los parques y espacios públicos aquí descrito, así como el hecho de que los habitantes han dejado de utilizarlos, ha propiciado el incremento de la delincuencia en estas áreas. Los vecinos, comentaron que no es conveniente pasar por los parques, especialmente de noche, pues son lugares donde asaltan; alguien se refirió a estos espacios públicos, como "bocas de lobo". También comentaron que en cuanto la inmobiliaria (Grupo SADASI) cesó de administrar el lugar dejó de haber vigilancia y con ello aumentó la delincuencia, especialmente en espacios públicos que cayeron en desuso por la falta de mantenimiento provocando lo que Dammert (2003) llama espacios inseguros.

Entre las situaciones delictivas que más se reportan, se encuentran: robos a casa habitación por la mañana y robo de autopartes por la noche, así como asaltos a transeúntes y transporte público en cualquier momento del día (Anónimo, Periódico digital, 2011).

Por otra parte, las casas no tenían cocheras cerradas. Esta situación ha sido aprovechada para el robo de autopartes, razón por la que algunos vecinos han optado por hacer cocheras con portones, provocando la formación de puntos ciegos, los cuales facilitan asaltos en la vía pública. Relatan los vecinos que la policía ha llegado a participar en algunos delitos. 


\section{La desorganización vecinal y su influencia en la delincuencia}

En Los Héroes no existe una organización vecinal para todo el fraccionamiento, sino que hay algunas pequeñas organizaciones al interior de las viviendas ubicadas en cerradas. Esta falta de organización general deriva en que la transgresión a las normas mínimas de vecindad sea común en la vida cotidiana, y se refleja en el abandono de las áreas comunes. Otra consecuencia evidente es la falta de sentido de comunidad para trabajar sobre problemas comunes, en especial la prevención de la delincuencia. Entre los efectos más destacados, producto de esta falta de organización encontramos:

Pérdida de control de accesos. A pesar de los intentos para formar algunos comités vecinales, estos no han funcionado pues existe un alto grado de desconfianza (Dammert,2003)

No se ha logrado realizar una asamblea general para instituir un comité vecinal, como lo marca la Ley de Condominios (Gobierno del Estado, 2003)

Derivado del punto anterior, no se ha logrado instituir un comité vecinal para el manejo de las cuotas. La cooperación es de $\$ 3.20$ dólares $^{2}$ mensuales por vivienda, sumando una cantidad aproximada de $\$ 34,370$ dólares, por lo tanto, se desconfía sobre el control que se pueda tener en el uso de esa cantidad.

Los parques están en total abandono, dando pie, como dijimos, a condiciones óptimas para la delincuencia, las cuales coinciden con las apreciaciones de Wilson y Kelling (2006)

\section{La (in) acción gubernamental}

En general, las acciones realizadas por el gobierno tienen un sentido reactivo: la policía actúa después de que ya se cometió el delito; para ello hace uso de la violencia física, la cual es su prerrogativa (Touraine, 2000). El Programa nacional para la prevención social de la violencia y la delincuencia, señala que la prevención queda en manos de la ciudadanía, deslindándose de esta manera de parte de su

\footnotetext{
2 Se considera un tipo de cambio de \$18.76 pesos mexicanos por dólar (al mes de mayo de 2017, mes en el que se cerró la investigación). Son $\$ 60$ por vivienda y un aproximado de $\$ 645000$ totales.
}

responsabilidad. Sin embargo, realiza algunas acciones "preventivas", por ejemplo, el Juzgado calificador del sector sur de la ciudad de Puebla organizó una reunión con vecinos en Los Héroes. La finalidad fue informar a los vecinos sobre las funciones de Juzgado, así como hacer énfasis en la diferencia entre una falta administrativa y un delito.

Cabe destacar que, de acuerdo con el Juzgado calificador, muchos de los delitos se podrían evitar, pues se derivan de faltas administrativas y de acciones realizadas por menores de edad, que normalmente carecen de supervisión y seguimiento por parte de los padres de familia. Por ello, señalan, la necesidad de la proximidad social entre vecinos, y entre estos y las autoridades.

Durante la participación de los vecinos en dicha reunión, se pudo notar la preocupación por el estado de descuido y abandono en el que se encuentran los parques y jardines del fraccionamiento, así como la falta de alumbrado público, pues consideran que ahí se cometen la mayoría de los delitos. Esto llevó a que se les hiciera ver la importancia de crear un consejo o comité vecinal para organizar el mantenimiento de estos espacios como lo sugieren diversos autores (Duhau y Giglia, 2008, Maya, 2008; Cohesión Comunitaria, 2010; y la misma Ley de Condominios (Gobierno del Estado, 2011), ya que el ayuntamiento no tiene capacidad para responder a todas estas necesidades sin ayuda $y$ colaboración de la organización vecinal.

Se percibe que en la autoridad no existe claridad sobre el significado profundo de la prevención y que intenta delegar la responsabilidad a los vecinos, pero no establece mecanismos de corresponsabilidad, mostrando lo que Touraine (2000) y Bauman 2006, consideran la debilidad de las instituciones gubernamentales.

Por otro lado, los vecinos tienen una visión paternalista al pensar que el gobierno debe resolver los problemas y no asumen compromisos, pues ningún vecino aceptó pertenecer a alguna organización o tener intenciones de iniciarla.

Otra de las acciones impulsadas por la policía es el programa "Vecinos vigilantes". Este funciona con base en grupos de ciudadanos que se organizan para pedir capacitación a la policía municipal sobre cómo actuar en caso de detectar actividad delictiva en su entorno. 
Después de la capacitación, los vecinos reciben lonas que identifican que están organizados, silbatos para dar señales de alerta, además de ser reconocidos como un comité. La policía se compromete a acudir al llamado de los vecinos en caso necesario. Es importante recalcar que la iniciativa debe ser de los ciudadanos; es decir, la policía no ve por la formación de los grupos ciudadanos.

Aunado a lo anterior, identificamos "acciones" para mejorar las condiciones del fraccionamiento que tienen un trasfondo de interés político proselitista. En 2016 se llevó a cabo una campaña de limpieza de uno de los parques (previo a las elecciones gubernamentales), convocada de boca en boca y a través de redes sociales. En esta actividad participaron aproximadamente 12 vecinos y una brigada de personas con playeras rojas, quienes aparentementen organizaban la actividad. El trabajo de los vecinos voluntarios no tuvo ninguna dirección, ya que cada uno hacía lo que consideraba conveniente (barrer, cortar hierba, etc.), lo cual refuerza la percepción de falta de organización vecinal. Casi a punto de concluir se presentó una persona que dijo ser candidato a diputado (el cual no estaba plenamente identificado), y dijo ser quien había convocado a la jornada de limpieza y dio un pequeño discurso en el que invitó a los vecinos a participar en acciones en favor de su comunidad. Esta acción no se repitió por parte de esta persona.

Una nueva convocatoria para hacer limpieza de otro de los parques la realizó una vecina del fraccionamiento. En este evento se juntaron 17 personas. Desde el inicio se vio su intención proselitista, pues la convocante llegó con una playera del Partido Acción Nacional (PAN), con el nombre del candidato a la gubernatura de Puebla. Se unieron 10 personas del partido, quienes llevaban banderas, así como juguetes para los niños que participaran en el evento. Al final regalaron botellas de agua y destacaron la preocupación de su candidato por la mejora del aspecto del fraccionamiento, así como su apoyo incondicional para lo mismo (el candidato no participó ni se hizo presente en ningún momento). Al igual que la experiencia anterior, no hubo ningún seguimiento por parte de los organizadores.

Estas acciones, muestra del clientelismo político, no se repitieron, por lo que los parques volvieron a las condiciones de descuido.

\section{La construcción de la organización vecinal, una medida para recuperar el espacio público}

Considerando que las condiciones urbanas son algo que difícilmente se puede modificar en términos tipomorfológicos, y que es poco probable que las leyes cambien, entonces la respuesta contra la delincuencia puede estar en la acción vecinal para la recuperación de los espacios públicos deteriorados y abandonados, ya que, como vimos, es en ellos donde más frecuentemente se dan las acciones delictivas y se percibe un alto grado de inseguridad. Sin embargo, en Los Héroes, existe poca consciencia de esto y las pocas acciones existentes son individuales $y$ otras provienen de incipientes "organizaciones" vecinales. Estas organizaciones se caracterizan por ser espontáneas, desarticuladas y con diferentes enfoques: religiosas, de vigilancia, medioambientales. No todas tienen efectos positivos.

Acciones individuales. Se constató la existencia de actores individuales que se sienten comprometidos con las condiciones en que se encuentran fraccionamiento. Por ello, llegan a realizar algunas acciones que no van más allá de sus límites personales o profesionales; tal es el caso del director de la escuela secundaria quien dio la orden para cerrar la explanada pública que da acceso a la escuela. Esto como una medida drástica ante su preocupación por un asesinato, consumo de alcohol y relaciones sexuales en la vía pública, así como la desaparición de una estudiante3. Aunque la colocación de la malla se realizó sin consultar a los vecinos, estos no pusieron objeción. Con esta medida los problemas se erradicaron en esa zona y ahora se mantiene limpia, pero ningún vecino puede hacer uso de ella.

Actualmente este parque solo se usa como zona de paso para ingresar a la escuela, y el resto del tiempo se mantiene cerrado, es decir, se perdió el espacio público.

La organización vecinal. En Los Héroes, la organización vecinal y el sentido de comunidad son prácticamente nulos. Las acciones más concretas se pueden ver en las "cerradas" al interior del fraccionamiento, donde los

3 Todo esto fue comentado por el director de la escuela secundaria "Faustino Salazar" en entrevista. 
vecinos se han organizado para mantenerlas en las mejores condiciones físicas y de seguridad.

Han colocado cámaras, rejas, alambradas de púas y lonas de "Vecino Vigilante" (según se apreció en las visitas de observación de campo). En pláticas informales con los vecinos mencionan que estas medidas les dan mayor seguridad ante la delincuencia, pero no alcanzan a dimensionar su aislamiento social con los vecinos que se encuentran fuera de su entorno inmediato.

Para los que tienen viviendas en calles abiertas ha sido más difícil organizarse. Existe desconfianza mutua, especialmente hacia los nuevos vecinos pues se desconoce de dónde provienen (Dammert, 2003). Se tiene recelo por el manejo del dinero, y difícilmente hacen aportaciones económicas o se reúnen para trabajar en conjunto, por lo que sus acciones son aisladas y desarticuladas. Se muestra un sentimiento de que cada uno debe cuidar lo suyo y a su familia; "si alguien los apoya, que bueno, si nadie lo hace, se cuidan solos" (pláticas informales con vecinos). Es decir, los vecinos no consideran que existen las condiciones para una relación de compromiso con los vecinos del fraccionamiento $y$, por lo tanto, no hay una organización vecinal con las bases propuestas por Duhau y Giglia (2008).

Impulsando la organización vecinal. Ante estas circunstancias se buscó la forma de generar lazos vecinales y comunitarios con base en la investigaciónacción (Checkland, 1993; Lewin, 1946). Una estrategia que se tuvo fue la de buscar grupos ya organizados al interior del fraccionamiento: las asociaciones de padres de familia, la iglesia y los grupos juveniles.

Se localizó un grupo de oración. Desde el primer acercamiento se vio buena voluntad para cooperar, sin embargo, cuando se propuso iniciar el trabajo fuera del templo para recuperar el espacio público, la respuesta fue nula.

Después de este intento, de manera fortuita se contactó al joven representante de una organización llamada "Salvemos los Parques" quien, junto con otro amigo, decidieron trabajar en la recuperación ecológica de uno de los parques del fraccionamiento Los Héroes. Consiguieron donaciones de algún material (machete, rastrillo, bolsas de basura y algunos volantes para difundir su proyecto) que les sirvió para empezar su cometido. Una vecina se ofreció a editar la redacción de los reportes de actividades que cada semana documentaban en Facebook.

El parque de la 119. Durante 15 meses se trabajó con Salvemos los Parques, realizando actividades de limpieza, poda y reforestación de uno de los parques del fraccionamiento (figura 6). Los jóvenes de Salvemos los Parques eligieron el ubicado en la 119 poniente, por ser el más cercano a sus domicilios. Las condiciones del parque eran deplorables, y provocaban gran inseguridad entre los vecinos. En pláticas con ellos, comentaban que:

[E]s muy peligroso pasar por este parque, especialmente cuando van solos (vecino 1 ).

[P]refiero rodear el parque pues ahí asaltan, solo paso por ahí cuando voy con mi esposo, pero en las noches no cruzamos por el parque (vecino 2 ).

Durante los primeros meses, se tuvo una buena participación de vecinos. Llegaron a participar hasta 15 personas. Algunas se acercaban a apoyar cuando veían el trabajo. La mayor parte de ellas participaron por el continua, pues la mayoría no regresó a la siguiente semana. En varias ocasiones los niños intentaron participar, pero sus padres se los llevaban alegando no tener tiempo.

Conforme pasaba el tiempo la gente apoyaba más con lo que podían, desde bolsas para basura, cubetas, refrescos, jarras de agua, o permitieron que se utilizara agua de sus tomas particulares para alguna actividad propia de la recuperación del parque, hasta llegaron a dar donativos económicos. Así, la confianza iba ganando terreno, Dammert (2003)

Con el paso del tiempo se empezaron a idear otro tipo de actividades para incentivar el interés de los vecinos. Con este fin se inició la formación de una composta y se hicieron comederos para aves. Adicionalmente se visitaron casas y negocios circundantes para invitar a la gente a participar. 


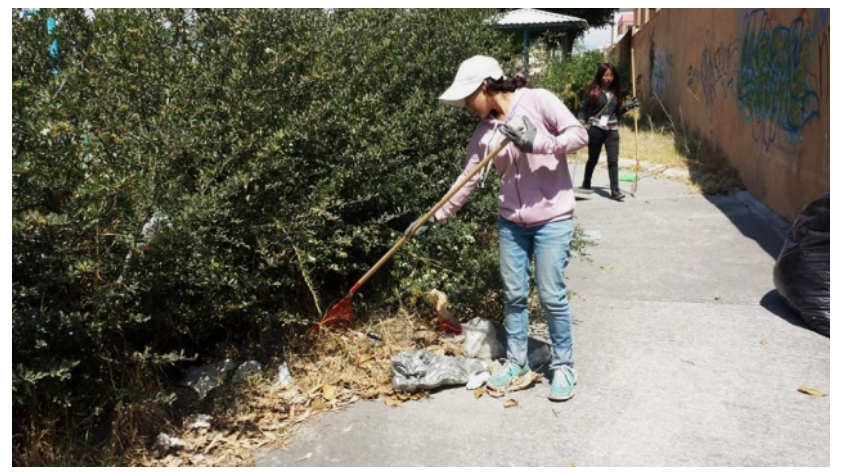

Figura 6. Parque de la 119. Trabajos de limpieza y poda del parque. Fuente: Juan Manuel Bautista Ramírez, 2015.

Wilson y Kelling (2006) y Averdijk (2011), mencionan que las condiciones de un espacio determinan el uso que de él se haga. En este sentido, el cambio en la imagen del parque (figura 7) fue radical por lo que empezó a ser usado de manera más continua e incluso en horarios nocturnos, pues los usuarios manifestaron sentirse más seguros.

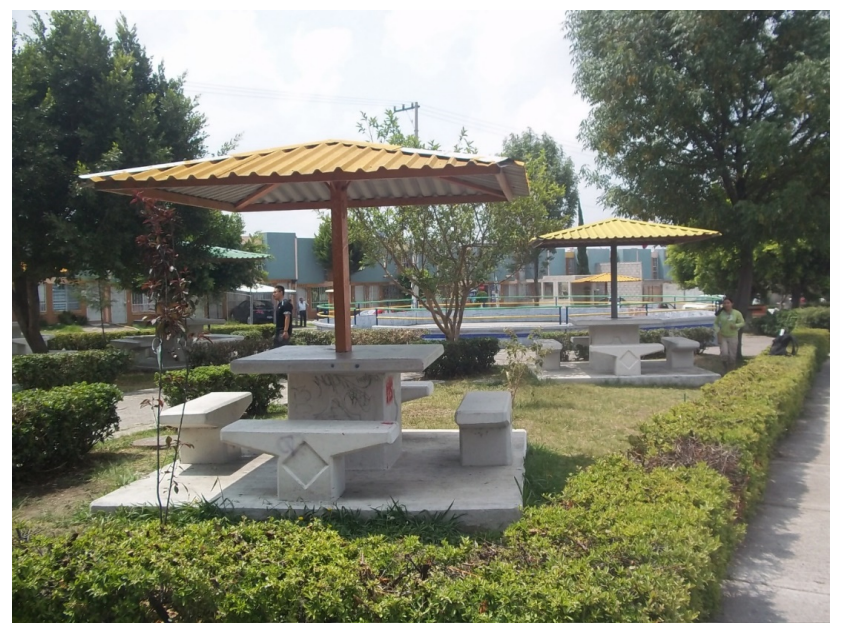

Figura 7. Resultados en el parque de la 119. El cambio es significativo, y la gente transita por el parque.

Fuente: Juan Manuel Bautista Ramírez, 2016

El parque de la guardería. Después de aproximadamente mes y medio de trabajo, el parque de la 119 empezó a verse en mejores condiciones, por lo que se tomó la decisión de iniciar el trabajo en otro parque: el de la "guardería". Se decidió trabajar en él ya que está junto a la guardería y al templo católico, se pretendía llamar la atención de los trabajadores y usuarios de ambos equipamientos.
Aun cuando el parque se encontraba en muy malas condiciones (figura 8), la participación efectiva fue únicamente de una señora. Por otro lado, aunque se estableció contacto con las autoridades de la guardería, no mostraron interés por apoyar.

Al no existir apoyo ni de las autoridades de la guardería, ni de los miembros de la comunidad católica, se decidió dejar de trabajar en el parque una vez que se dejó limpio y con los arbustos y pasto recortados. Desafortunadamente, el parque ya luce igual que cuando se empezó a trabajar en él.

Por otra parte, la ubicación del parque de la 119, rodeado de casas, ayudó a que la respuesta inicial de los vecinos fuera de mayor participación. No fue así con el parque de la guardería, donde la proximidad con la iglesia y la guardería hace que la gente solo pase por este parque y no sea parte de su actividad cotidiana.

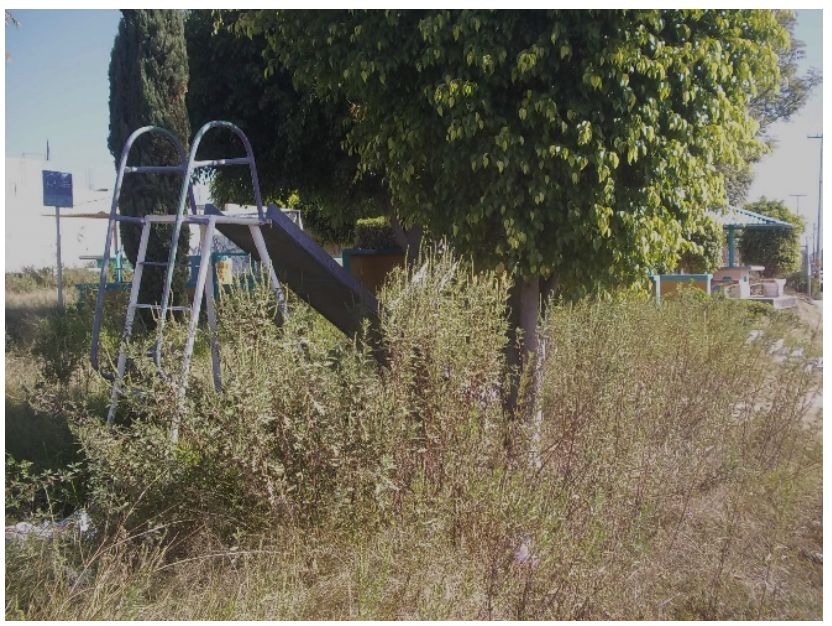

Figura 8. ¿Dónde jugarán los niños? Condiciones iniciales del parque de la Guardería.

Fuente: Juan Manuel Ramírez Bautista, 2016.

Campañas de reforestación. A petición del fundador de Salvemos los parques, la Secretaría de Medio Ambiente del Municipio de Puebla donó 160 árboles. Estos fueron utilizados para reforestar cuatro de los parques del fraccionamiento, en tres jornadas diferentes. La promoción para la participación en esta actividad fue de puerta en puerta a las viviendas circundantes a los parques y colocando letreros en casas y negocios.

Estas jornadas de reforestación fueron de las actividades que más apoyo recibieron. Podemos decir 
que hubo una buena participación; sin embargo, el porcentaje de participación fue de " $70 \%$ externos y $30 \%$ vecinos" (Salvemos los parques, 2016). Lamentablemente, los vecinos no se organizaron para dar mantenimiento a los árboles sembrados, por lo que, durante el invierno, la mayoría se secaron.

A pesar de la indiferencia generalizada, estas acciones despertaron el interés de algunos vecinos $y$ empieza a haber reconocimiento y cooperación con Salvemos los parques.

Otras acciones aisladas de vecinos organizados. Se encontraron otro tipo de acciones por parte de los habitantes, como el de los autollamados vigilantes nocturnos. A raíz del incremento delictivo en una de las calles no cercanas a los parques, se organizaron grupos de cinco o seis personas en pequeños comités de calle. Cada uno de estos tiene designados días y horarios en los que salen a vigilar las calles entre las 11 de la noche y seis de la mañana.

"Armados" con palos, escobas, tubos y lámparas, efectúan rondines por las calles asignadas. Su función es la de hacer presencia y que se note que los vecinos están vigilando. Ellos mismos saben que es muy alto el riesgo, pero sienten que han disuadido el delito, pues se ha reducido el número de autos estacionados con ocupantes que parecen en actitud sospechosa, además de que han logrado identificar a gente en actividades fuera de lo normal. De esta manera actúan para prevenir el delito, pero existe la posibilidad de que se enfrenten directamente con delincuentes.

\section{Conclusiones}

La experiencia en Los Héroes demuestra que existe una respuesta gubernamental fallida para atender el incremento de la delincuencia en fraccionamientos cerrados. Desde los instrumentos de planeación, como la Ley de Fraccionamientos, se crean condiciones de inseguridad para los habitantes al dejarlos fuera de la ciudad consolidada y sin ser sujetos de servicios mínimos como salud, seguridad, mantenimiento de espacios públicos, etc.
Se identifican acciones impregnadas de prácticas añejas proselitistas sin sentido de servicio, ya que actores políticos las promueven, pero normalmente son aisladas, sin seguimiento e intrascendentes. En la gestión de la seguridad, el Estado delega gran parte de la responsabilidad a los habitantes de los fraccionamientos a través de la Ley de Condominios, y que difícilmente se pone en práctica.

El caso Los Héroes demuestra que hay una incipiente organización vecinal sin visión de comunidad. La magnitud del fraccionamiento lleva a generar microescalas organizacionales (en cerradas o fragmentos de calles), a partir de acciones individuales desarticuladas y con un fuerte sentimiento de desconfianza entre los vecinos.

El trabajo realizado para la recuperación del espacio público demuestra que las acciones colectivas con enfoques medioambientales (como los trabajos de limpieza y poda de parques, así como las campañas de reforestación) atraen más la participación vecinal. El mejoramiento del espacio público tiene un impacto visual inmediato y genera confianza en el uso del espacio, favoreciendo el incremento de la actividad y por lo tanto el encuentro y reconocimiento entre los habitantes, lo cual lleva a una incipiente formación de organización vecinal, así como a la reducción de la percepción de inseguridad.

La visión del estado paternalista prevalece en el consciente colectivo que, aunado a la desconfianza hacia las autoridades, ha ocasionado un letargo considerable en la organización vecinal y en el fomento a la participación en corresponsabilidad con el gobierno local.

Los procesos de formación de identidad y fortalecimiento de organizaciones vecinales son muy largos y con altibajos, por lo que la posibilidad de su existencia depende de identificar actores clave, como Salvemos los parques, deseosos de participar y organizar, así como momentos de oportunidad para fomentar el trabajo colectivo.

Es imperante que la sociedad civil, unida con la autoridad y otras instituciones que aún generan confianza, como la universidad, puede incidir desde el territorio para transformarlo $\mathrm{y}$, con ello, reducir la delincuencia [B] 


\section{Referencias}

Anónimo. Periódico digital en línea. (3 de octubre de 2011). https://bit.ly/2GT5qMa

Averdijk, M. (2011). Reciprocal effects of victimization and routine activities. Journal of Quantitative Criminology, (27)2, 125-149. Recuperado de https://bit.ly/2ETxoFJ

Azaola, H. (2013). La violencia de hoy. Las violencias de siempre. En N. Arteaga Botello (Coord.), La violencia en México (p.p. 25-60). Madrid: Catarata

Bauman, Z. (2009). Tiempos líquidos. Vivir en una época de incertidumbre. México: Tusquets

Checkland, P. (1993). Pensamiento de sistemas, práctica de sistemas, México: LIMUSA

Cohesión comunitaria e innovación social para fundación este país. (2010). Del tejido social a la cohesión comunitaria. Una aproximación inicial para México. Recuperado de https://bit.ly/2SqpNkS

Dammert, L. (2003). Participación Comunitaria en Prevención del Delito en América Latina, en ¿De qué participación hablamos?, Santiago: Centro de Estudios del Desarrollo. Recuperado de www.policiaysociedad.org

Duhau, E. y Giglia, A. (2008). Las reglas del desorden: habitar la ciudad. México. Siglo XXI Editores, Universidad Metropolitana Unidad Azcapotzalco. Recuperado de https://bit.ly/2BVYXub

Esquivel, M. T., Maya, E. y Cervantes, J. (2005). La promoción privada y los grandes conjuntos habitacionales: nuevas modalidades de acceso a la vivienda. Scripta Nova. Revista electrónica de geografía y ciencias sociales (IX)194. Recuperado de http://www.ub.es/geocrit/sn/sn-194-21.htm

Fonseca, J.M. (2014-2015). La importancia y la apropiación de los espacios públicos en las ciudades, Paakat. Revista de Tecnología y Sociedad, 4(7). Recuperado de http://www.udgvirtual.udg.mx/paak at/index.php/paakat/article/view/222/329

Gobierno del Estado de Puebla (2003). Ley de fraccionamientos y acciones urbanísticas del Estado Libre y Soberano de Puebla. Recuperado de https://bit.ly/2GUsnOG
Gobierno del Estado de Puebla (2011). Ley que regula el régimen de propiedad en condominio para el Estado de Puebla. Recuperado de http://www.ordenjuridico.gob.mx/Documentos/Estat al/Puebla/wo105241.pdf

Gobierno de la República (2013). Plan Nacional de Desarrollo 2013-2018. Recuperado de http://pnd.gob.mx/

Gobierno de la República (2014). Programa Nacional para la Prevención Social de la Violencia y la Delincuencia 2014-2018. Recuperado de http://www.dof.gob.mx/nota_detalle.php?codigo=53 43087\&fecha $=30 / 04 / 2014$

Gobierno de la República (2016). Plan Nacional de Desarrollo 2006-2012. Recuperado de http://pnd.gob.mx/

González, G.M. (2015). (In)seguridad humana: elementos mínimos para discutir. Ciudades, (105), 2-8.

Google Maps. Mapas e imágenes satelitales. (Figuras). Recuperado de https://www.google.com.mx/maps/

Jasso López, C. (2013). Percepción de inseguridad en México. Revista Mexicana de Opinión Pública, 15, 1329. Recuperado de: http://www.revistas.unam.mx /index.php/rmop/article/view/43663/39599

Kessler, G. (2009), El sentimiento de inseguridad: sociología del temor al delito, Buenos Aires: Siglo XX Editores

Larsen, B. Ф., Kleif, H. B., \& Kolodziejczyk, C. (2015). The volunteer programme 'Night Ravens': a difference-indifference analysis of the effects on crime rates. Journal of Scandinavian Studies in Criminology \& Crime Prevention, (16), 2-24. https://doi.org/10.1080/14043858.2015.1015810

Lewin, K. (1946). Action research and minority problems. Journal of Social Issues, 2(4), 34-46. https://doi.org/10.1111/i.1540-4560.1946.tb02295.x

Maya, E. y Cervantes, J.F. (2008). La importancia del espacio exterior en los conjuntos habitacionales en la zona metropolitana de la ciudad de México. Bitácora, 13, 47-56. 
Roitman, S. (2004). Urbanizaciones cerradas: estado de la cuestión y propuesta teórica. Revista de Geografía Norte Grande, 32, 5-19. Recuperado de https://www.redalyc.org/html/300/30003201/

Salvemos los parques.(2016) Página de información en Facebook. Recuperado de https://www.facebook. com/salvemoslosparques14/?ref=aymt homepage $p$ anel
Touraine, A., (2000), ¿Podremos vivir juntos? México: Fondo de Cultura Económica

Wilson, J. Q. \& Kelling, G.L. (2006), Broken Windows. En V.E. Kappeler, The police and society, (p.p. 154-167), U.S.A.: Eastern Kentucky University-Waveland Press, Inc. 